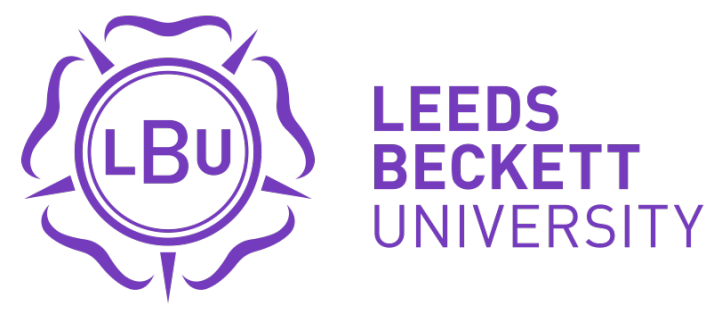

Citation:

Hendricks, S and Till, KA and Weaving, D and Powell, A and Kemp, S and Stokes, $\mathrm{K}$ and Jones, B (2019) Training, Match and Non-Rugby Activities in Elite Male Youth Rugby Union Players in England. International journal of Sports Science and Coaching, 14 (3). pp. 336-343. ISSN 1747-9541 DOI: https://doi.org/10.1177/1747954119829289

Link to Leeds Beckett Repository record:

https://eprints.leedsbeckett.ac.uk/id/eprint/5607/

Document Version:

Article (Accepted Version)

The aim of the Leeds Beckett Repository is to provide open access to our research, as required by funder policies and permitted by publishers and copyright law.

The Leeds Beckett repository holds a wide range of publications, each of which has been checked for copyright and the relevant embargo period has been applied by the Research Services team.

We operate on a standard take-down policy. If you are the author or publisher of an output and you would like it removed from the repository, please contact us and we will investigate on a case-by-case basis.

Each thesis in the repository has been cleared where necessary by the author for third party copyright. If you would like a thesis to be removed from the repository or believe there is an issue with copyright, please contact us on openaccess@leedsbeckett.ac.uk and we will investigate on a case-by-case basis. 


\title{
Training, Match and Non-Rugby Activities in Elite Male Youth Rugby Union Players in England
}

\author{
Hendricks, S.; Till, K. A.; Weaving, D.; Powell, A.; Kemp, S.; Stokes, K.; Jones, B.
}

\section{ABSTRACT}

Rugby union is a late specialization sport, as a consequence youth players may still be engaged in other activities and sports throughout the year as they transition to rugby specialization. Limited research exists quantifying rugby union training and matches, as well as engagement in other activities and sports. Therefore, the aim of this study was to quantify and compare rugby union training, matches and other activities of elite youth U15 and $\mathrm{U} 16$ rugby union players at different stages of the season. Four-hundred and ninety-two youth (Under-15 and 16-year-old) rugby union players self-reported the frequency, intensity and duration of their participation in rugby union matches, rugby union training, gym, physical education and other sports during three different stages (September to December [Sept-Dec], January to April [Jan-Apr], May to August [May-Aug]) of the year When all activities were combined, the frequency and volume of rugby matches and training was the greatest during the Sept - Dec stage. The frequency and volume of participating in other sports increased in the May-Aug stage of the season. Gym training frequency, intensity, and duration were stable across the year for both U15 and U16 players. Coaches and practitioners working with elite youth rugby union players should be aware that players are still participating in other activities outside of rugby training and competition. Coaches and practitioners should put structures in place to plan and monitor players' activities in order to optimise the positive outcomes of specialisation (e.g., expertise) while reducing the potential negative outcomes (e.g., injury, burnout).

Keywords: youth; rugby union; development; training; talent identification 


\section{INTRODUCTION}

Rugby union is a contact-skill based, intermittent, high-intensity invasion sport, involving periods of static exertions, collisions and running, interspersed with variable periods of lower intensity work and rest ${ }^{1-4}$. Within England, the national governing body, the Rugby Football Union (RFU), facilitates the identification and development of talented youth rugby union players via fourteen Regional Rugby Union Academies. These fourteen Regional Rugby Union Academies are also aligned with their respective professional rugby union clubs ${ }^{5}$. Players are typically identified from amateur clubs or schools and invited to train within a Regional Rugby Union Academy in Under 15 (U15) and U16 academy squads prior to some signing a professional contract at 18 years of age. During this period, players may train and compete within multiple rugby union programmes (i.e., club, school, academy) alongside other sporting activities and school-based commitments (e.g., Physical Education $\left.{ }^{6}\right)$, resulting in a complex multi-sport environment ${ }^{7}$.

Youth athletic development encompasses the training of health-, skill-, and performancerelated components of fitness ${ }^{8}$. The aims of athletic development programmes are to develop healthy, capable and resilient young athletes, while attaining widespread, inclusive, sustainable and enjoyable participation and success across all levels of individual athletic achievement ${ }^{8-10}$. To achieve these aims, athlete development programmes integrate health-, skill-, and performance-related components of fitness with the developmental age of the athlete, depending on the sport ${ }^{8}$. For team sports for example, adolescence (typically girls aged 12-18 years and boys aged 14-18 years) is the period where an athlete may begin to specialise in a particular sport (before this period, young athletes are encouraged to participate in a range of sports). In athlete development models, this is referred to as the "specialization years", where the frequency, intensity and duration of training and competition increases for that particular sport ${ }^{11,12}$. In most athlete development programmes, this period also coincides with the identification and recruitment of 'talented' athletes ${ }^{13,14}$. Similar development and talent identification programmes are employed in rugby union, whereby participants are encouraged to participate in numerous sports prior to specializing during the adolescent period ${ }^{15}$. The transition period, when athletes change from participating in multiple sports to focussing on one sport is particularly challenging for 
coaches and practitioners working in youth rugby union. This is due to players commonly still participating in other sports while the frequency, intensity, duration and volume of training and competition in rugby union increases ${ }^{6,16}$. Therefore, regardless of the talent identification and development and programme employed, sporting organisations and governing bodies need to be aware of the potential positive (e.g., enhanced fitness) and negative outcomes (e.g., injury, overtraining, burnout) associated with such programmes and whether the implementation is aligned to the overall aim of youth athletic development $8-10,12,17$.

Research into training, matches and sporting activity of youth rugby union players is emerging 6,7, 18-21. These studies have examined the training activity of Australian National youths ${ }^{21}, 16-18$ year old English school and academy players ${ }^{20}$, as well as session and weekly analysis using global positioning system technology within one rugby union academy $6,7,19$. This research is limited by a small sample across multiple ages ${ }^{21}$, lack of quantification of training frequency, intensity and duration ${ }^{20}$ or focused on one club setting ${ }^{6}$. To date, no study has attempted to quantify the frequency, intensity, duration and volume of training, matches and sporting activities of elite youth rugby union players. Such information would help coaches and policy makers better understand player activity across the game to build strategies towards healthy athletic development.

While quantifying the training, matches and sporting activities of elite youth rugby union players is important, an understanding of the differences between the stages of the season warrants specific investigation. Over a 12 month period, the English rugby union season can be divided into three stages. Stage 1; the school rugby union season, which is between the start of the academic term and the Christmas break; September-December. Stage 2; the non-school rugby union season, where players still participate in rugby union (and other codes) between the start of the new year and (approximately) the Easter break; JanuaryApril. Stage 3; the non-rugby season, where players may participate in other sports; MayAugust. To reduce the risk of injury and optimize the performance and well-being of the athlete, each stage has a different profile in terms of frequency, intensity and duration of rugby union training and matches ${ }^{22}$. Youth rugby union players however, may still be engaged in other activities and sports throughout the year as they transition to rugby 
specialization, which may impede their recovery and development. With that said, limited research exists quantifying rugby union training and matches, as well as engagement in other activities and sports by the stage of the season. Therefore, the aim of this study was to quantify and compare the rugby union training, matches and other sporting activities of elite youth U15 and U16 rugby union players at different stages of the season.

\section{METHODS}

\section{Study Design}

The study used a cross-sectional design, whereby U15 and U16 players self-reported the frequency, intensity and duration of i) playing rugby union matches, ii) participation in rugby union training, iii) participation in gym training, iv) participation in other sports, and v) participation in physical education (PE) activities during different stages of the previous season (i.e., September to December (Sept-Dec); January to April (Jan-Apr); May to August (May-Aug)) based on the English rugby union season and structure.

\section{Participants}

Data were collected from U15 and U16 male rugby union players from all 14 Regional Rugby Union Academies in England. This equated to a total of 492 participants ( $n=131 \mathrm{U} 15$ players and $n=361$ U16 players; see Table 1 for descriptive characteristics). These players were identified as 'talented' based on their performance at their local club or school, and selected by a Regional Rugby Union Academy. Players in these Regional Rugby Union Academies are considered elite youth rugby players. Participation in the study was voluntary with player written assent and coaches informed consent obtained. Each participant's parent or guardian was also informed of the study, and had the opportunity to opt-out. Ethics approval was granted by the University's ethics board.

\section{***Insert Table 1 Here***}

Table 1. Descriptive characteristics of participants in Jan-Apr 2016

\section{Data collection}

A training, matches and sporting activity questionnaire was developed to capture information on the frequency (number of times), intensity (how hard) and duration (how 
long, in minutes) players participated in rugby union matches, rugby union training, gym (i.e., weight or resistance) training, other sports and PE in a typical week, during the different stages of the rugby union season (Sept-Dec; Jan-Apr; May-Aug) (questionnaire can be requested from the contact author). A questionnaire was used because it was the most pragmatic approach given the purpose and context of the study. The reliability and validity of this specific questionnaire was not tested, however, similar work in other team sports has shown that participation recall questionnaires are reliable and valid ${ }^{23,24}$.

Based on the stage of the season, players reported the frequency, intensity and duration for each activity during a typical week. Definitions of what is considered a rugby union match, rugby union training, gym (weight) training, other sports and PE were provided, as well as definitions for frequency and duration. Players reported the associated numbers from the verbal anchors (e.g., 5 = hard) from a modified Borg category ratio-10 (CR-10) scale ${ }^{25}$.

Data were collected at residential training camps that included scheduled research sessions. During the research session, players were organised into a room where they were introduced to the researchers and briefed on the purpose of the study. Thereafter, specific instructions on how to complete the questionnaire were provided. The researcher(s) were present throughout the session to address any questions. For the U16 cohort, data were collected at the U16 Rugby Festival Week where all 14 teams were located in Wellington, United Kingdom. For the U15 cohort, data were collected at four regional rugby union training camps (Leeds, Coventry, Bristol, and Guilford).

\section{Statistical Analyses}

The reported frequency and duration of each activity were multiplied to calculate volume of participation (i.e., frequency $X$ duration $=$ minutes per week $(\mathrm{min} / \mathrm{wk}))$. Thereafter, frequency, intensity, duration and volume of participation for each activity (i.e., rugby union training, rugby union matches, gym training, PE and other sports) were compared between season stages (Sept to Dec, Jan to Apr, May to Aug) using a one-way analysis of variance (ANOVA). Data are reported as mean and standard deviation (SD) and separated by age group (U15 and U16). Volume is reported for each specific activity and combined activities to show total activity volume (min/wk). Because of the cross-sectional study design, stages 
of the season were treated as independent groups. The frequency mean ( \pm SD) for each activity was calculated using the total number of participants as the denominator (U15 $\mathrm{n}=131, \mathrm{U16} \mathrm{n}=361$ ). The Bonferroni post-hoc test was used to further analyse any differences when the $\mathrm{F}$ value was significant. A two-tailed $p$-value was used for all tests, with the a priori alpha level of significance set at $p<0.05$. In addition, Cohen's effect size (ES) statistics with $90 \%$ confidence interval $(90 \% \mathrm{Cl})$ were calculated with $\mathrm{ES}$ of $<0.2,0.2$ $0.59,0.6-1.19$, and $1.2>$ considered trivial, small, moderate, and large, respectively ${ }^{26}$. Statistical analyses were performed using STATA ${ }^{\circledR}$ version 12 (StataCorp LP, USA) and Prism 6 (GraphPad software, USA).

\section{RESULTS}

\section{Under 15}

The reported frequencies, session intensities (rating, 1-10) and duration (minutes) of activities during a typical week for each stage of season for U15 players are shown in Table 2. The volume of rugby matches was significantly greater during Sept-Dec (116 $\pm 57 \mathrm{~min} / \mathrm{wk}$; $p<0.001, E S=1.42 \pm 0.22)$ and Jan-Apr $(97 \pm 61 \mathrm{~min} / \mathrm{wk} ; \mathrm{p}<0.001, E S=1.07 \pm 0.21)$ than MayAug (33 $\pm 60 \mathrm{~min} / \mathrm{wk}$, Figure 1). Likewise, the volume of rugby training was significantly greater during Sept-Dec (337 $\pm 163 \mathrm{~min} / \mathrm{wk} ; \mathrm{p}<0.001$, ES = $1.40 \pm 0.22)$ and Jan-Apr $(282 \pm$ $166 \mathrm{~min} / \mathrm{wk} ; \mathrm{p}<0.001, \mathrm{ES}=1.00 \pm 0.21)$ than May-Aug (138 $\pm 118 \mathrm{~min} / \mathrm{wk})$. The volume of participation in Other Sports was significantly lower in Sept-Dec (62 $\pm 99 \mathrm{~min} / \mathrm{wk}$ ) than JanApr (102 $\pm 115 \mathrm{~min} / \mathrm{wk} ; \mathrm{p}<0.01, \mathrm{ES}=0.37 \pm 0.12)$ and May-Aug $(173 \pm 241 \mathrm{~min} / \mathrm{wk} ; \mathrm{p}<0.001$ $\mathrm{ES}=0.60 \pm 0.13)$.

\section{***Insert Table 2 Here ${ }^{* * *}$}

Table 2: U15 frequencies, session intensities (rating, 1-10) and duration (minutes) of activities during a typical week for each stage of season. Data are reported as mean ( \pm SD).

\section{***Insert Figure 1 Here***}

Figure 1: Activity specific and combined volumes (minutes/week) for U15 and U16 by stage of the season. Data are reported as mean ( \pm SD). 
The reported frequencies, session intensities (rating, 1-10) and duration (minutes) of activities during a typical week for each stage of season for U16 players are shown in Table 3. The volume of rugby matches was significantly greater during Sept-Dec (105 \pm 68 $\mathrm{min} /$ week; $p<0.001, E S=1.36 \pm 0.14)$ and Jan-Apr $(85 \pm 71 \mathrm{~min} / \mathrm{wk} ; \mathrm{p}<0.001, E S=0.99 \pm 0.13)$ than May-Aug (24 $\pm 50 \mathrm{~min} / \mathrm{wk}$; Figure 1). Similarly, the volume of rugby training was significantly greater during Sept-Dec $(310 \pm 197 \mathrm{~min} / \mathrm{wk} ; \mathrm{p}<0.001, \mathrm{ES}=0.70 \pm 0.13)$ and Jan$\operatorname{Apr}(252 \pm 171 \mathrm{~min} /$ week; $\mathrm{p}<0.001, \mathrm{ES}=0.45 \pm 0.12)$ than May-Aug $(164 \pm 220 \mathrm{~min} / \mathrm{wk})$. The volume of participation in Other Sports was significantly lower in Sept-Dec (41 \pm 77 $\mathrm{min} /$ week) than Jan-Apr (66 $\pm 109 \mathrm{~min} / \mathrm{wk} ; \mathrm{p}<0.05, \mathrm{ES}=0.26 \pm 0.12)$ and May-Aug $(114 \pm 171$ $\min / w k ; p<0.001, E S=0.55 \pm 0.12$ ).

\section{***Insert Table 3 Here***}

Table 3: U16 frequencies, session intensities (rating, 1-10) and duration (minutes) of activities during a typical week for each stage of season. Data are reported as mean ( $\pm S D$ ).

\section{DISCUSSION}

This study quantified the training, matches and sporting activities (i.e., frequency, intensity, duration and volume) of youth U15 and U16 English academy rugby union players and compared the activities between stages of season. Findings showed that when all activities are combined, players completed an average of 10-11 sessions per week between Sept and Dec and Jan-Apr, equating to approximately 12 hours of activity per week. This finding demonstrates the different environments that 15-16 year old rugby union players are exposed to during a week, which supports previous research on youth rugby union players ${ }^{6}$ 20, 21 . Also, within each activity, frequency and volume of activities varied between players for both age categories. Previous research within one English Regional Rugby Union Academy ${ }^{7}$ demonstrated large between subject variability in training duration (30-135\%) and large within subject variability in training load (i.e., duration $\mathrm{x}$ intensity; 6-78\%). One explanation for this variation between players within each activity can be explained by the late specialization talent development programme implemented in England (e.g., not all players participating in the same programme, as per senior professional rugby union). Findings also showed that during a typical week, players total volume of training and 
activities were more than 600 minutes during Sept and Dec and Jan-Apr, which is higher than previously reported for Australian youth rugby union players ${ }^{21}$. The relatively high volume of training and activities for this cohort of youth rugby players highlights potential concerns surrounding the transition period during late specialization sports ${ }^{8,16}$. Considering the positive (e.g., increased fitness, psycho-social benefits) and negative (e.g., injury, burnout) outcomes associated with sporting activity ${ }^{9,10,12}$, coaches and practitioners should monitor and manage training, competition and sporting activities of elite youth rugby union players.

Players reported an average of 1.5-1.8 rugby union matches per week between Sept-Dec, with 3.6-4.1 rugby union training sessions. Furthermore, the volume of rugby union matches and training was significantly greater in Sept-Dec, while training intensity was significantly greater in May-Aug for training than the other two stages for both age groups. This may represent youth rugby union players participate in traditional adult-like 'pre-season' training, whereby intensity is usually increased ${ }^{27}$ or indeed other factors (e.g., weather, training modality) may influence perceived training intensity. In addition to this, players also participated in PE and other sports. For the U15 players, PE was stable for frequency, intensity, and duration across the stages of the season, whereas for the U16 players, almost no PE sessions were reported for May-Aug, which may be representative of academic examination periods and summer vacation. For both age groups, the intensity of PE sessions were regarded as moderate. The frequency and volume of participating in other sports increased in the May-Aug stage of the season. The intensity of other sports however, remained somewhat hard to hard throughout the year. These results support Phibbs et al., 7 , who reported that youth rugby union players within a professional rugby union academy have high loads from exposure to various sports and sports teams. How these exposures to various activities throughout the year influences the physical development ${ }^{18,28}$ or injury risk ${ }^{29}$ of players is currently unclear. However, coaches and practitioners need to be aware of these demands on young athletes transitioning to rugby specialization.

In addition to field-based training, youth athletes should also participate in supervised resistance training, for both performance and health benefits ${ }^{8,16,30}$. Current findings showed that gym training frequency, intensity, duration and volume were stable across the 
year for both $\mathrm{U} 15$ and $\mathrm{U} 16$ players. Weakley et al., ${ }^{18}$ reported weekly participation in resistance training activities of $1.4 \pm 0.6$ sessions per week during a 12-week observational period in youth rugby union and found that frequency, nor duration or intensity relates to their physical development. Therefore, while it is a positive that youth players are undertaking gym resistance training, further research may need to examine the gym resistance training practices to ensure appropriate training methodologies are employed for optimising player development ${ }^{31}$.

\section{Practical Applications}

- Coaches and practitioners working with elite youth rugby union players should be aware that players are still participating in other activities outside of rugby training and matches.

- Coaches and practitioners should put structures in place to plan and monitor players' activities in order to optimise the positive outcomes of specialisation (e.g., expertise) while reducing the potential negative outcomes (e.g., injury).

\section{CONCLUSIONS}

This study quantified the training, competition and sporting activities (i.e., frequency, intensity, duration, and volume) of youth U15 and U16 English academy rugby union players and compared the activities between stages of season. Findings demonstrated that youth rugby union players aged 15-16 years undertake multiple activities including rugby training, rugby matches, gym, PE and other sports throughout the year, supporting the RFU's talent development programme as a late specialization model. However, with this late specialization programme, there are inherent challenges in managing and monitoring the activities of players due to the multi-sport, environment and coach programmes. Findings showed that when all activities are combined, players completed an average of 10-11 sessions per week during the competitive stage of the season. Players reported an average of 1.5-1.8 rugby matches per week with 3.6-4.1 rugby training sessions, but it unclear how this influences their physical development, injury risk and well-being. This study forms a basis for subsequent work in the area. Future studies can compare the self-reported 
frequency, intensity and duration of activities to the team's training plan and competition schedule, as well as the coach's knowledge of a player's scheduling demands. Furthermore, future studies can test the relationship between the player's scheduling demands and outcome measures such injury, performance or well-being.

\section{Limitations and future research}

This study is the first to describe self-reported frequency, intensity, duration and volume of training, matches and sporting activities in 492 young English rugby union players enrolled within Regional Rugby Union Academy programmes and it is not without its limitations. Firstly, although similar work in other team sports have shown that similar questionnaires are reliable and valid ${ }^{23,24}$, the reliability and validity of this specific questionnaire was not formally tested. To formally test the psychometric properties of the questionnaire, the reported frequencies, intensities and durations can be compared to the actual training plan and competition schedule. A similar questionnaire can also be developed for coaches and practitioners. This information will not only help determine the psychometric properties of the player questionnaire, but also provides insight into the coach's knowledge of the scheduling demands of elite rugby union players.. The current study required players to report frequency, intensity and duration based a typical week during each stage of the season of the past year. As such, the potential for recall bias should be acknowledged. To address this limitation, data can be collected within the specific stage of the season or every month. While the current study was holistic from the perspective of collecting all activities players participated in, it did not ask players to report other potential loads, such as academic or life stress ${ }^{32}$. Also, although the ultimate goal of this research is to improve the welfare of youth athletes, this study did not collect any outcome measures such as injury, performance or well-being. These measurements should be considered when designing future studies. 


\section{REFERENCES}

1. Hendricks S, van Niekerk T, Sin DW, et al. Technical determinants of tackle and ruck performance in International rugby union. J Sports Sci 2017;36(5):522-28.

2. Read DB, Jones B, Phibbs PJ, et al. Physical demands of representative match-play in adolescent rugby union. J Strength Cond Res 2017;31(5):1290-96.

3. McLaren SJ, Weston M, Smith A, et al. Variability of physical performance and player match loads in professional rugby union. J Sci Med Sport 2016;19(6):493-97.

4. Read D, Weaving D, Phibbs $P$, et al. Movement and physical demands of school and university rugby union match-play in England. BMJ Open Sport \& Exerc Med 2017;2(1):e000147.

5. Union ERF. Playing Careers - England Rugby Academies. 2017

6. Phibbs PJ, Jones B, Read DB, et al. The appropriateness of training exposures for matchplay preparation in adolescent schoolboy and academy rugby union players. J Sports Sci 2017:1-6.

7. Phibbs PJ, Jones B, Roe $\mathrm{G}$, et al. Organised chaos in late specialisation team sports: Weekly training loads of elite adolescent rugby union players. J Strength Cond Res 2017; 32(5), 1316-1323.

8. Lloyd RS, Oliver JL, Faigenbaum AD, et al. Long-term athletic development-part 1: a pathway for all youth. J Strength Cond Res 2015;29(5):1439-50.

9. Lloyd RS, Cronin JB, Faigenbaum AD, et al. National Strength and Conditioning Association position statement on long-term athletic development. J Strength Cond Res 2016;30(6):1491-509.

10. Bergeron MF, Mountjoy M, Armstrong N, et al. International Olympic Committee consensus statement on youth athletic development. Br J Sports Med 2015;49(13):843-51.

11. Till K, Jones B, Darrall-Jones J, et al. Longitudinal development of anthropometric and physical characteristics within academy rugby league players. J Strength Cond Res 2015;29(6):1713-22.

12. Rongen F, Cobley S, McKenna J, et al. 3 Talent identification and development. Health and Elite Sport: Is High Performance Sport a Healthy Pursuit? 2014;38:33. 
13. Till K, Morley D, O'Hara J, et al. A retrospective longitudinal analysis of anthropometric and physical qualities that associate with adult career attainment in junior rugby league players. J Sci Med Sport 2017; 20(11), 1029-1033.

14. Cobley SP, Till K. Participation trends according to relative age across youth UK Rugby League. Int J Sport Sci Coach 2017:1747954117710506.

15. Hendricks S. Trainability of junior Rugby Union players. S Afr J Sports Med 2012;24(4):122-26.

16. Lloyd RS, Oliver JL, Faigenbaum AD, et al. Long-term athletic development, part 2: barriers to success and potential solutions. J Strength Cond Res 2015;29(5):1451-64.

17. Soligard T, Schwellnus M, Alonso J-M, et al. How much is too much?(Part 1) International Olympic Committee consensus statement on load in sport and risk of injury. Br J Sports Med 2016;50(17):1030-41.

18. Weakley JJ, Till K, Darrall-Jones J, et al. Strength and Conditioning Practices in Adolescent Rugby Players: Relationship with Changes in Physical Qualities. J Strength Cond Res 2017; Online first.

19. Phibbs PJ, Jones B, Roe GA, et al. We know they train, but what do they do? Implications for coaches working with adolescent rugby union players. Int J Sports Sci Coach 2017;12(2):175-82.

20. Palmer-Green DS, Stokes KA, Fuller CW, et al. Training activities and injuries in English youth academy and schools rugby union. Am J Sports Med 2015;43(2):475-81.

21. Hartwig TB, Naughton G, Searl J. Defining the volume and intensity of sport participation in adolescent rugby union players. Int J Sports Phys Perf 2008;3(1):94-106.

22. Gamble P. Periodization of Training for Team Sports Athletes. Strength Cond J 2006;28(5):56-66.

23. Drake D, Breslin G. Developmental activities and the acquisition of perceptual-cognitive expertise in international field hockey players. Int J Sports Sci Coach 2018;13(5):636642.

24. Ward P, Hodges NJ, Starkes JL, et al. The road to excellence: Deliberate practice and the development of expertise. High Abil Stud 2007;18(2):119-53.

25. Foster C, Florhaug JA, Franklin J, et al. A new approach to monitoring exercise training. J Strength Cond Res 2001;15(1):109-15. 
26. Hopkins W, Marshall S, Batterham A, et al. Progressive statistics for studies in sports medicine and exercise science. Med Sci Sport Exerc 2009;41(1):3-12.

27. Black CJ, Till K, O’Hara JP, et al. Top secret training data? External training loads of a cup winning English Super League rugby league team. Int J Sports Sci Coach 2017:1747954117711094.

28. Darrall-Jones JD, Jones B, Till K. Anthropometric, sprint, and high-intensity running profiles of English academy rugby union players by position. J Strength Cond Res 2016;30(5):1348-58.

29. Palmer-Green DS, Stokes KA, Fuller CW, et al. Match injuries in English youth academy and schools rugby union: an epidemiological study. Am J Sports Med 2013;41(4):74955.

30. Faigenbaum AD, Kraemer WJ, Blimkie $C J$, et al. Youth resistance training: updated position statement paper from the national strength and conditioning association. $J$ Strength Cond Res 2009;23:S60-S79.

31. Weakley JJ, Till K, Read DB, et al. The effects of traditional, superset, and tri-set resistance training structures on perceived intensity and physiological responses. Euro J Appl Physiol 2017;117(9):1877-89.

32. Mann JB, Bryant KR, Johnstone B, et al. Effect of physical and academic stress on illness and injury in division 1 college football players. J Strength Cond Res 2016;30(1):2025. 
Table 1. Descriptive characteristics of participants in Jan-Apr 2016

\begin{tabular}{lcccc}
\hline & \multicolumn{2}{c}{ U15 } & \multicolumn{2}{c}{ U16 } \\
& Mean & $\pm S D$ & Mean & $\pm S D$ \\
\hline Age (years) & 15.5 & 0.5 & 16.5 & 0.6 \\
Height (cm) & 178.0 & 19.5 & 179.4 & 12.2 \\
Body Mass (kg) & 81.1 & 12.8 & 86.3 & 14.0 \\
Playing Age (years) & 8.5 & 3.0 & 8.7 & 3.4 \\
Gym Age* (years) & 3.0 & 3.9 & 2.7 & 3.1 \\
\hline
\end{tabular}

*Players were asked what age they started weight training 
Table 2: U15 reported frequencies, session intensities (rating, 1-10) and duration (minutes) of activities during a typical week for each stage of season. Data are reported as mean ( \pm SD).

\begin{tabular}{|c|c|c|c|c|c|c|c|}
\hline & \multicolumn{3}{|c|}{ Stage of Season } & \multirow{2}{*}{$\begin{array}{c}\text { Overall } \\
\text { Effect } \\
\text { ( } p \text { value) }\end{array}$} & \multicolumn{3}{|c|}{ P-value (ES $\pm 90 \% \mathrm{Cl}$ ) } \\
\hline & $\begin{array}{l}\text { Sept-Dec } \\
\text { (Stage 1) }\end{array}$ & $\begin{array}{l}\text { Jan-Apr } \\
\text { (Stage 2) }\end{array}$ & $\begin{array}{l}\text { May-Aug } \\
\text { (Stage 3) }\end{array}$ & & Stage 1 vs 2 & Stage 2 v 3 & Stage 1 v 3 \\
\hline \multicolumn{8}{|l|}{ Frequency } \\
\hline $\begin{array}{l}\text { Rugby } \\
\text { Matches }\end{array}$ & $1.8 \pm 0.8$ & $1.5 \pm 0.9$ & $0.5 \pm 1.0$ & $<0.001$ & $\begin{array}{c}0.015 \\
(0.45 \pm 0.21)\end{array}$ & $\begin{array}{c}<0.001 \\
(1.26 \pm 0.22)\end{array}$ & $\begin{array}{c}<0.001 \\
(1.44 \pm 0.23)\end{array}$ \\
\hline $\begin{array}{l}\text { Rugby } \\
\text { Training }\end{array}$ & $4.1 \pm 1.6$ & $3.4 \pm 1.6$ & $1.6 \pm 1.0$ & $<0.001$ & $\begin{array}{c}<0.001 \\
(0.44 \pm 0.21)\end{array}$ & $\begin{array}{c}<0.001 \\
(1.35 \pm 0.23)\end{array}$ & $\begin{array}{c}<0.001 \\
(1.87 \pm 0.24)\end{array}$ \\
\hline Gym & $2.0 \pm 1.3$ & $2.0 \pm 1.2$ & $2.1 \pm 1.5$ & 0.781 & $\begin{array}{c}1.00 \\
(0.00 \pm 0.20)\end{array}$ & $\begin{array}{c}1.00 \\
(0.07 \pm 0.20)\end{array}$ & $\begin{array}{c}1.00 \\
(0.07 \pm 0.20)\end{array}$ \\
\hline Other Sports & $0.9 \pm 1.2$ & $1.5 \pm 1.5$ & $1.9 \pm 1.8$ & $<0.001$ & $\begin{array}{c}0.004 \\
(0.44 \pm 0.20)\end{array}$ & $\begin{array}{c}0.173 \\
(0.24 \pm 0.20)\end{array}$ & $\begin{array}{c}<0.001 \\
(0.65 \pm 0.20)\end{array}$ \\
\hline PE & $1.9 \pm 1.3$ & $1.9 \pm 1.3$ & $1.6 \pm 1.4$ & 0.161 & $\begin{array}{c}1.000 \\
(0.00 \pm 0.20)\end{array}$ & $\begin{array}{c}1.000 \\
(0.22 \pm 0.20)\end{array}$ & $\begin{array}{c}1.000 \\
(0.22 \pm 0.20)\end{array}$ \\
\hline $\begin{array}{c}\text { Sum } \\
\text { Frequency } \\
\text { Intensity } \\
\text { (rating, 1-10) }\end{array}$ & $10.7 \pm 1.2$ & $10.3 \pm 0.8$ & $7.7 \pm 0.6$ & $<0.001$ & $\begin{array}{c}<0.001 \\
(0.39 \pm 0.21)\end{array}$ & $\begin{array}{c}<0.001 \\
(3.68 \pm 0.33)\end{array}$ & $\begin{array}{c}<0.001 \\
(3.16 \pm 0.30)\end{array}$ \\
\hline $\begin{array}{l}\text { Rugby } \\
\text { Matches }\end{array}$ & $6.6 \pm 2.1$ & $6.7 \pm 2.2$ & $6.6 \pm 2.2$ & 0.857 & $\begin{array}{c}1.000 \\
(0.05 \pm 0.20)\end{array}$ & $\begin{array}{c}1.000 \\
(0.05 \pm 0.20)\end{array}$ & $\begin{array}{c}1.000 \\
(0.00 \pm 0.20)\end{array}$ \\
\hline $\begin{array}{l}\text { Rugby } \\
\text { Training }\end{array}$ & $5.2 \pm 1.4$ & $5.4 \pm 1.5$ & $5.8 \pm 1.9$ & 0.010 & $\begin{array}{c}0.635 \\
(0.19 \pm 0.20)\end{array}$ & $\begin{array}{c}0.176 \\
(0.29 \pm 0.20)\end{array}$ & $\begin{array}{c}0.007 \\
(0.36 \pm 0.20)\end{array}$ \\
\hline Gym & $6.2 \pm 1.6$ & $6.0 \pm 1.6$ & $6.1 \pm 1.6$ & 0.669 & $\begin{array}{c}1.000 \\
(0.13 \pm 0.20)\end{array}$ & $\begin{array}{c}1.000 \\
(0.06 \pm 0.20)\end{array}$ & $\begin{array}{c}1.000 \\
(0.06 \pm 0.20)\end{array}$ \\
\hline Other Sports & $4.9 \pm 1.9$ & $4.9 \pm 1.7$ & $4.7 \pm 1.7$ & 0.789 & $\begin{array}{c}1.000 \\
(0.00 \pm 0.20)\end{array}$ & $\begin{array}{c}1.000 \\
(0.12 \pm 0.20)\end{array}$ & $\begin{array}{c}1.000 \\
(0.11 \pm 0.20)\end{array}$ \\
\hline PE & $3.6 \pm 1.5$ & $3.6 \pm 1.5$ & $3.5 \pm 1.5$ & 0.987 & $\begin{array}{c}1.000 \\
(0.00 \pm 0.20)\end{array}$ & $\begin{array}{c}1.000 \\
(0.07 \pm 0.20)\end{array}$ & $\begin{array}{c}1.000 \\
(0.07 \pm 0.20)\end{array}$ \\
\hline $\begin{array}{c}\text { Mean } \\
\text { Intensity } \\
\text { Duration } \\
\text { (minutes) }\end{array}$ & $5.3 \pm 2.0$ & $5.3 \pm 2.0$ & $5.4 \pm 2.1$ & 0.603 & $\begin{array}{c}1.000 \\
(0.00 \pm 0.20)\end{array}$ & $\begin{array}{c}1.000 \\
(4.08 \pm 0.35)\end{array}$ & $\begin{array}{c}1.000 \\
(4.08 \pm 0.35)\end{array}$ \\
\hline $\begin{array}{l}\text { Rugby } \\
\text { Matches }\end{array}$ & $65.6 \pm 15.0$ & $67.2 \pm 16.2$ & $65.6 \pm 20.0$ & 0.734 & $\begin{array}{c}1.000 \\
(0.10 \pm 0.20)\end{array}$ & $\begin{array}{c}1.000 \\
(0.09 \pm 0.20)\end{array}$ & $\begin{array}{c}1.000 \\
(0.00 \pm 0.20)\end{array}$ \\
\hline $\begin{array}{l}\text { Rugby } \\
\text { Training }\end{array}$ & $83.4 \pm 16.8$ & $83.7 \pm 20.4$ & $88.4 \pm 34.5$ & 0.240 & $\begin{array}{c}1.000 \\
(0.02 \pm 0.20)\end{array}$ & $\begin{array}{c}0.443 \\
(0.17 \pm 0.20)\end{array}$ & $\begin{array}{c}0.378 \\
(0.18 \pm 0.20)\end{array}$ \\
\hline Gym & $64.5 \pm 22.2$ & $62.6 \pm 21.1$ & $63.0 \pm 22.4$ & 0.812 & $\begin{array}{c}1.000 \\
(0.09 \pm 0.20)\end{array}$ & $\begin{array}{c}1.000 \\
(0.02 \pm 0.20)\end{array}$ & $\begin{array}{c}1.000 \\
(0.07 \pm 0.20)\end{array}$ \\
\hline Other Sports & $77.1 \pm 41.9$ & $79.1 \pm 31.0$ & $104.0 \pm 77.4$ & 0.004 & $\begin{array}{c}1.000 \\
(0.05 \pm 0.20)\end{array}$ & $\begin{array}{c}0.013 \\
(0.42 \pm 0.20)\end{array}$ & $\begin{array}{c}0.015 \\
(0.43 \pm 0.20)\end{array}$ \\
\hline PE & $62.2 \pm 21.9$ & $64.0 \pm 26.5$ & $64.0 \pm 26.3$ & 0.831 & $\begin{array}{c}1.000 \\
(0.07 \pm 0.20)\end{array}$ & $\begin{array}{c}1.000 \\
(0.00 \pm 0.20)\end{array}$ & $\begin{array}{c}1.000 \\
(0.07 \pm 0.20)\end{array}$ \\
\hline $\begin{array}{c}\text { Mean } \\
\text { Duration }\end{array}$ & $70.1 \pm 24.2$ & $71.3 \pm 24.5$ & $77.2 \pm 44.7$ & 0.001 & $\begin{array}{c}1.000 \\
(0.07 \pm 0.20)\end{array}$ & $\begin{array}{c}0.012 \\
(0.39 \pm 0.20)\end{array}$ & $\begin{array}{c}0.002 \\
(0.44 \pm 0.20)\end{array}$ \\
\hline
\end{tabular}


Table 3: U16 reported frequencies, session intensities (rating, 1-10) and duration (minutes) of activities during a typical week for each stage of season. Data are reported as mean ( \pm SD).

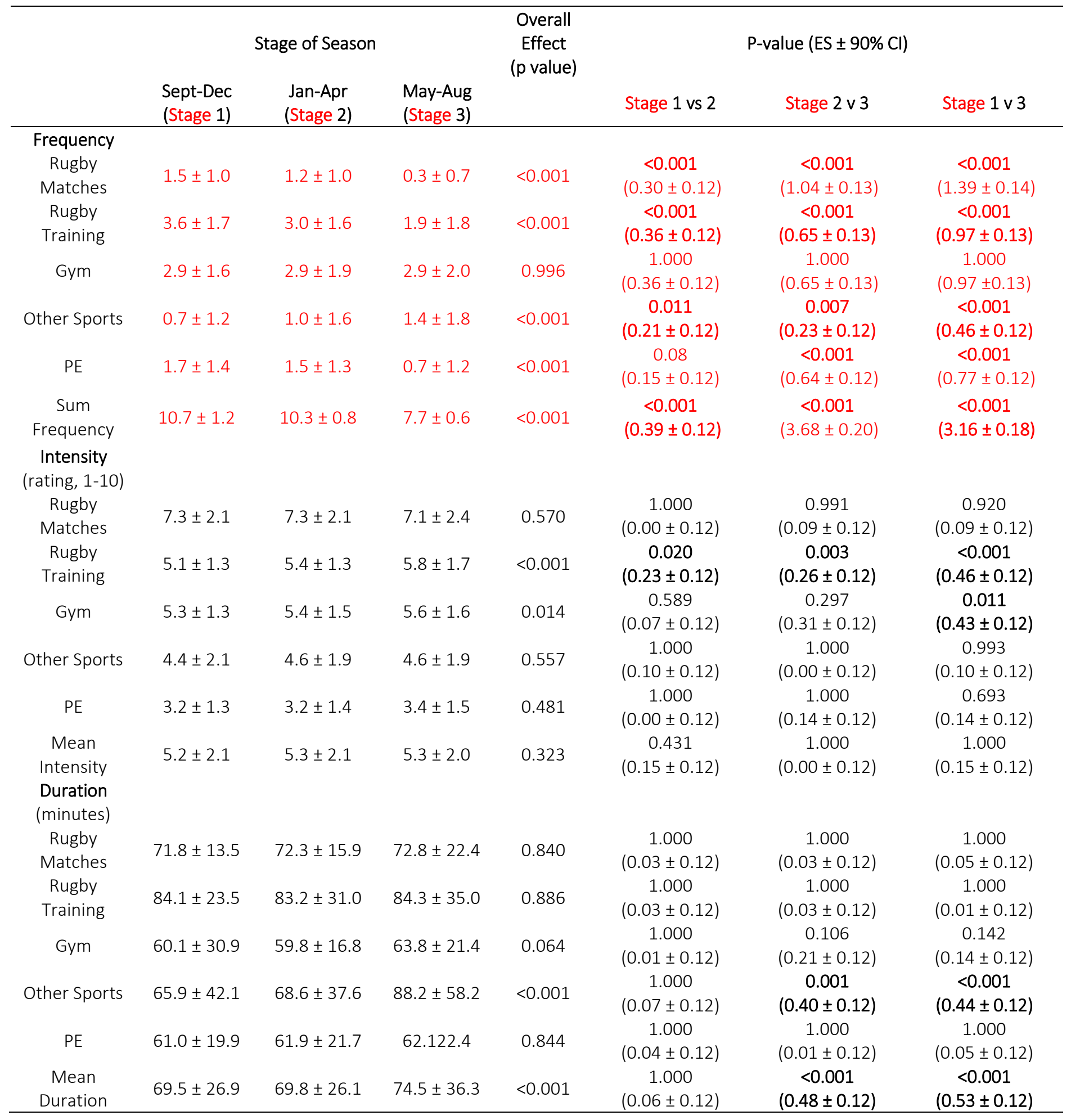



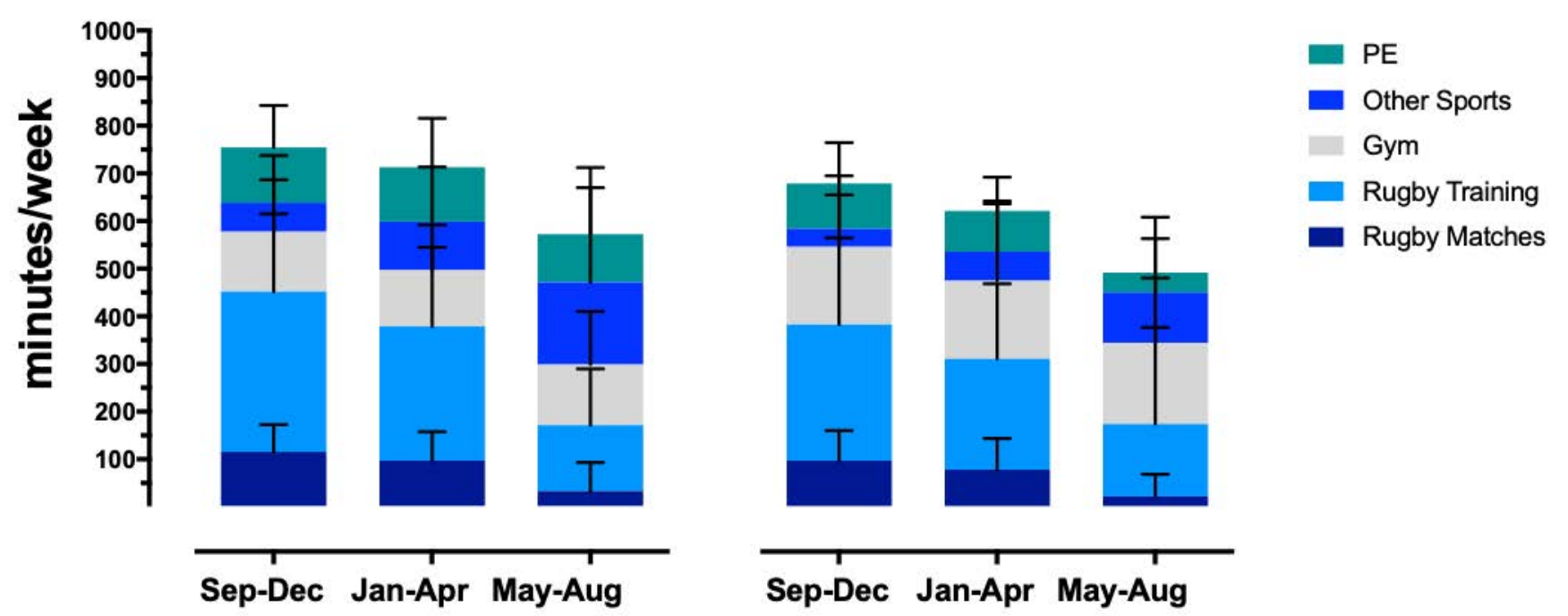